\title{
Quaternary chalcogenides: Promising thermoelectric material and recent progress
}

\author{
Teng Wang ${ }^{1 \dagger}$, Taichang Huo ${ }^{1 \dagger}$, Hongchao Wang ${ }^{1,2^{*}}$ and Chunlei Wang ${ }^{1 *}$
}

Depletion of natural resources (oil, gas and coal) and increasing global warming urge the researchers to develop new methods for energy harvesting. The world's demand of alternative clean energy is becoming more and more drastic. The conversion of waste heat into useful electrical energy is an eco-friendly and straight forward approach to solve the worldwide power problems. Thermoelectric (TE) materials have been considered to relieve the energy crisis based on the reversible heat and electricity conversion [1-3]. TE generators have drawn great attention due to their numerous advantages such as eco-friendly energy conversion, no pollutants, no moving parts, wide temperature range applications, long life span, small size and no toxic residuals. Thus the TE energy conservation is expected to be an attractive way to solve the energy crisis. TE generators can convert heat from daily life heat sources like vehicles, factories and computers or even from human bodies to electrical energy. Along with power production, TE materials have the ability to replace traditional refrigerating methods by using Peltier effect since they do not emit greenhouse gases. However, low conversion efficiency limits the commercial applications of TE generators.

The efficiency of a TE module is determined by dimensionless figure of merit $(z T) . z T$ is related to Seebeck coefficient $(S)$, thermal conductivity $(\kappa)$ and electrical conductivity $(\sigma), z T=S^{2} \sigma T / \kappa=S^{2} \sigma T /\left(\kappa_{\mathrm{e}}+\kappa_{\mathrm{L}}\right)$, where $T$ is the absolute temperature, $\kappa_{\mathrm{e}}$ is the thermal conductivity due to electrons and holes, $\kappa_{\mathrm{L}}$ is the thermal conductivity from photons (moving through lattice) and $S^{2} \sigma$ is the power factor $(P F)$ [4]. It is clear that $z T$ can be improved by increasing $\sigma$ and $S$, or by decreasing $\kappa$. But the fact is that these parameters are relevant to each other, so it is feasible to synergistically optimize the TE parameters to achieve a high $z T$ [5]. The excellent electrical perfor- mance has been obtained through carrier concentration optimization [6], band engineering [7], resonant levels $[8,9]$ and electron energy filtering $[10,11]$. As for decreasing the thermal conductivity, ground breaking progress has been achieved mainly due to the introduction of the nano engineering into TE area [12].

As mentioned above, $S, \sigma$ and $\kappa$ are interdependent with each other through the carrier concentration. Thus, synergistic effect should be taken into account for enhancing the figure of merit when optimizing the electrical properties. But the lattice thermal conductivity is a relative individual parameter, thus materials with intrinsic low thermal conductivity are potential candidates for achieving higher $z T$. Many materials with extremely low intrinsic thermal conductivity have been reported such as $\mathrm{Yb}_{14} \mathrm{MnSb}_{11}\left(z T_{\max } \sim 1.0\right)$ [13], single crystal SnSe $\left(z T_{\max } \sim\right.$ 2.6) [14], and quaternary chalcogenides $\left(z T_{\max } \sim 0.6\right)$ [1517]. Especially, quaternary chalcogenides, which have been utilized in many areas, e.g., optical materials [18], have gained attention in TE area due to their extremely low thermal conductivity. The quaternary chalcogenides possess a pseudo-cubic crystal structure. This special crystal structure can block the propagation of the phonons due to the local non-cubic lattice distortion which is the key of the low lattice thermal conductivity. Furthermore, the pseudo-cubic crystal structure can be viewed as a long ranged nearly cubic framework in which the highly degenerated electrical bands at band edges can be achieved for excellent electrical properties. Thus a simultaneous optimization of the electrical and thermal transport properties can be reached in the quaternary chalcogenides $[19,20]$. Based on these advantages, many excellent studies have been done to promote the TE property of the quaternary chalcogenides, and new concepts and synthesis methods have been employed in this

\footnotetext{
${ }^{1}$ School of Physics, State Key Laboratory of Crystal Materials, Shandong University, Jinan 250100, China

${ }^{2}$ State Key Laboratory of Metastable Materials Science and Technology, Yanshan University, Qinhuangdao 066000, China

† These authors contributed equally to this work.

*Corresponding authors (emails: wanghc@sdu.edu.cn (Wang H); wangcl@sdu.edu.cn (Wang C))
} 
material. Thus it is deserved to draw the researcher's attentions to $\mathrm{Cu}_{2} \mathrm{~B}^{\mathrm{II}} \mathrm{C}^{\mathrm{IV}} \mathrm{Se}_{4}$ group which are considered as a promising TE material.

\section{CRYSTAL STRUCTURES AND TE PERFORMANCES OF QUATERNARY CHALCOGENIDES}

Quaternary chalcogenides have common composition of $\mathrm{Cu}_{2} \mathrm{~B}^{\mathrm{II}} \mathrm{C}^{\mathrm{IV}} \mathrm{X}_{4}$ where $\mathrm{B}=\mathrm{Zn}, \mathrm{Cd}, \mathrm{Mn}, \mathrm{Hg} ; \mathrm{C}=\mathrm{Si}, \mathrm{Ge}, \mathrm{Sn}$ and $\mathrm{X}=\mathrm{Se}, \mathrm{S}, \mathrm{Te}$. Among these quaternary compounds, $\mathrm{Cu}_{2}(\mathrm{Zn}, \mathrm{Mn}, \mathrm{Cd}, \mathrm{Fe}, \mathrm{Co}) \mathrm{SnSe}_{4}$ are often investigated as the remarkable TE materials. The typical crystal structure of quaternary compound $\mathrm{Cu}_{2}(\mathrm{Zn}, \mathrm{Mn}, \mathrm{Cd}, \mathrm{Fe}, \mathrm{Co}) \mathrm{SnSe}_{4}$ group is shown in Fig. 1. The quaternary compounds all have the tetragonal lattice structure which is also called the low-symmetry non-cubic structure. This structure can be described as a double-periodic cubic zinc-blende supercell in the $z$-direction. All atoms have a tetrahedral surrounding, and the tetrahedron is formed by selenium and metal atoms. Every selenium atom is surrounded by four metal atoms. Cationic elements form a tetrahedral void with anionic Se atoms residing inside it. The difference of electronegativity between cations and variant interatomic distances results in natural superlattice structure with localized lattice distortions. And the structure distortion parameter $\eta(\eta=c / 2 a$, where $c$ and $a$ are the lattice parameters along the $z$-axis and $x$-axis, respectively) is usually used to describe the compression $(<1)$ or tension $(>1)$ in the crystal lattice. The complex structure has different bonding lengths and bonding angles between the cations and the Se anions. For example, in the quaternary $\mathrm{Cu}_{2} \mathrm{MnSnSe}_{4}$, the initial $\mathrm{Zn}$ cations are substituted by three different cations $(\mathrm{Cu}, \mathrm{Mn}$, and $\mathrm{Sn})$ with different electronegativities. These three different cations form distinct chemical bonds with the Se anions with different bonding lengths, such as $2.41 \AA$ for $\mathrm{Cu}-\mathrm{Se}$, $2.52 \AA$ for $\mathrm{Mn}-\mathrm{Se}$, and $2.58 \AA$ for Sn-Se [21]. Compared

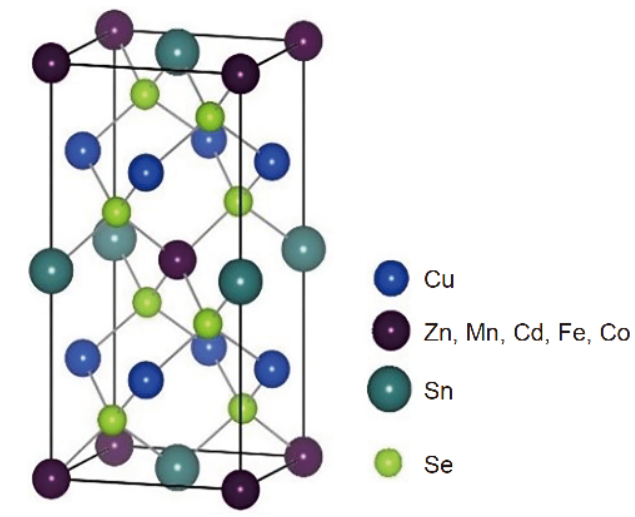

Figure 1 Crystal structure of quaternary chalcogenides $\mathrm{Cu}_{2} \mathrm{~B}^{\mathrm{II}} \mathrm{C}^{\mathrm{IV}} \mathrm{X}_{4}(\mathrm{~B}$ $=\mathrm{Zn}, \mathrm{Cd}, \mathrm{Mn}, \mathrm{Hg} ; \mathrm{C}=\mathrm{Si}, \mathrm{Ge}, \mathrm{Sn} ; \mathrm{X}=\mathrm{Se}, \mathrm{S}, \mathrm{Te})$.

with traditional cubic TE alloys, the complex structure plays an effective role in phonon scattering which consequently leads to a low lattice thermal conductivity as shown in Fig. 2a. In the middle and high temperature range, the lattice thermal conductivity of the quaternary chalcogenides is smaller than that of SiGe [21-24]. And the lattice thermal conductivities of pure phase $\mathrm{Cu}_{2} \mathrm{MnSnSe}_{4}, \mathrm{Cu}_{2} \mathrm{FeSnSe}_{4}$ and $\mathrm{Cu}_{2} \mathrm{CoSnSe}_{4}$ are even smaller than that of the commercial $\mathrm{PbTe}$ which possesses heavy atom mass $[21,25]$. Thus the distorted structure induced low intrinsic lattice thermal conductivity guarantee the $\mathrm{Cu}_{2} \mathrm{~B}^{\mathrm{II}} \mathrm{C}^{\mathrm{IV}} \mathrm{Se}_{4}$ compounds are potential TE material candidates.

Instead, the inferior electrical property is the limit of $\mathrm{Cu}_{2} \mathrm{~B}^{\mathrm{II}} \mathrm{C}^{\mathrm{IV}} \mathrm{X}_{4}$ to obtain good TE properties. Referred to the electrical transport properties, the band structures of these compounds play a crucial role. Quaternary alloys have much larger band gap, e.g., $1.41 \mathrm{eV}$ for $\mathrm{Cu}_{2} \mathrm{ZnSnSe}_{4}$ and $0.98 \mathrm{eV}$ for $\mathrm{Cu}_{2} \mathrm{CdSnSe}_{4}$ as compared with traditional alloy materials [22,25]. Additionally, the low carrier mobility due to the heavy bands also influences the
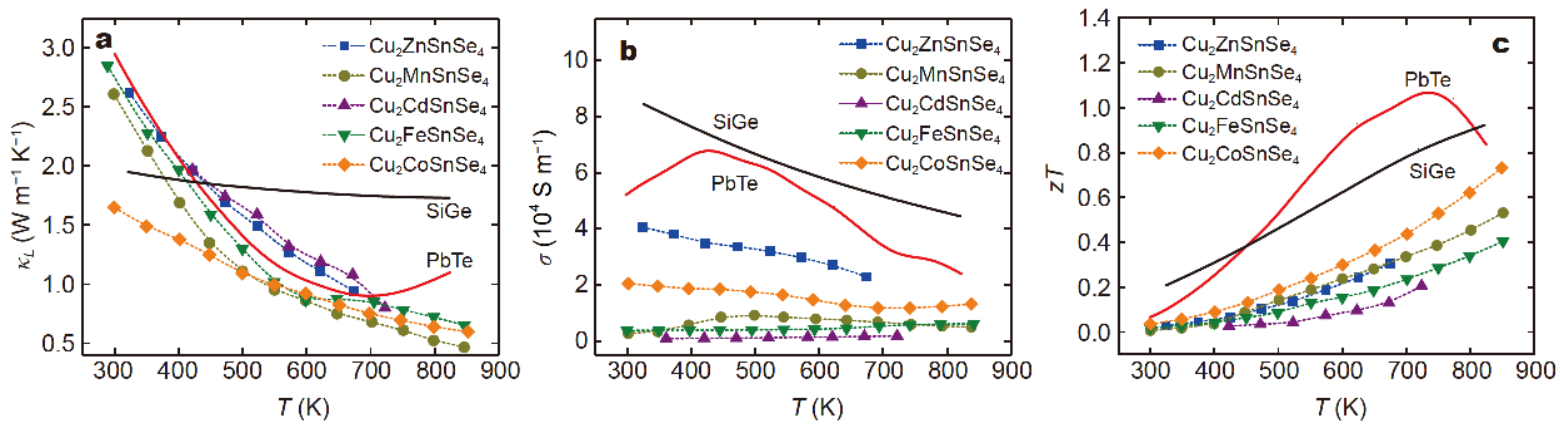

Figure 2 Comparison of the intrinsic (a) lattice thermal conductivity, (b) electrical conductivity, and (c) figure of merit of $\mathrm{Cu}_{2} \mathrm{ZnSnSe}_{4}$ [23], $\mathrm{Cu}_{2} \mathrm{MnSnSe}_{4}$ [21], $\mathrm{Cu}_{2} \mathrm{CdSnSe}_{4}$ [24], $\mathrm{Cu}_{2} \mathrm{FeSnSe}_{4}$ [21], $\mathrm{Cu}_{2} \mathrm{CoSnSe}_{4}$ [21], PbTe [25] and SiGe [22]. 
transportation of the carriers. Wide band gap and low carrier mobility result in lower electrical conductivity in these compounds than that of the alloy materials as shown in Fig. 2b $[26,27]$. The small values $\left(<4 \times 10^{4} \mathrm{~S} \mathrm{~m}^{-1}\right)$ of the electrical conductivity for $\mathrm{Cu}_{2} \mathrm{~B}^{\mathrm{II}} \mathrm{C}^{\mathrm{IV}} \mathrm{X}_{4}$ are the striking contrast to that of $\mathrm{SiGe}$ and $\mathrm{PbTe}$ which are almost among $4 \times 10^{4}$ to $8 \times 10^{4} \mathrm{~S} \mathrm{~m}^{-1}$ in the whole temperature range. Consequently, the $z T \mathrm{~s}$ of these pure phase quaternary chalcogenides are smaller than that of $\mathrm{PbTe}$ or $\mathrm{SiGe}$ as shown in Fig. 2c. Thus the low electrical conductivity is the main restriction for the quaternary chalcogenides to achieve a high $z T$.

Despite the intrinsic low thermal conductivity of the quaternary compounds, it is highly desirable to further improve the TE properties of this system, especially for the enhancement of the electrical properties. It shows that by using appropriate techniques, such as doping, band engineering and nano-structuring, quaternary compounds show excellent TE performance. Some widely used methods are discussed in detail in this perspective.

\section{STRATEGIES FOR IMPROVING ELECTRICAL PROPERTIES OF QUATERNARY CHALCOGENIDES}

While the intrinsic low thermal conductivity is an advantage of quaternary chalcogenides as candidate of $\mathrm{TE}$ materials, the poor electrical properties of pure phase quaternary chalcogenides limits their TE performances. The defective $P F$ mainly results from the huge electrical resistivity of the quaternary chalcogenides originating from the wide band gap and low carrier mobility as illustrated before. Though a higher $S$ can be achieved in wide band gap semiconductors, the diminishing $P F$ due to the huge electrical resistivity is vital. Thus the key for improving the electrical properties and consequently the $P F$ of this material is to reduce the electrical resistivity. For this purpose, progress has been made via the varia- tions in stoichiometry and cation doping.

The variation in stoichiometry, also named non-stoichiometry, is actually inducing excessive $\mathrm{Cu}$ to substitute the $\mathrm{B}$ or $\mathrm{C}$ site in $\mathrm{Cu}_{2} \mathrm{~B}^{\mathrm{II}} \mathrm{C}^{\mathrm{IV}} \mathrm{Se}_{4}$. The stem of doping excessive $\mathrm{Cu}$ to optimize the electrical resistivity is mainly due to two aspects. Firstly, the valance state of $\mathrm{Cu}$ in the stoichiometric $\mathrm{Cu}_{2} \mathrm{~B}^{\mathrm{II}} \mathrm{C}^{\mathrm{IV}} \mathrm{Se}_{4}$ is +1 which is lower than the valance states of $\mathrm{B}^{\mathrm{II}}$ or $\mathrm{C}^{\mathrm{IV}}$, and thus additional holes will be created via excessive $\mathrm{Cu}$ doping [28]. Secondly, the conversion of insulating paths to conducting pathways occurs with excessive $\mathrm{Cu}$ doping. As mentioned in Fig. 1, the crystal structure of $\mathrm{Cu}_{2} \mathrm{~B}^{\mathrm{II}} \mathrm{C}^{\mathrm{IV}} \mathrm{Se}_{4}$ can be regarded as composed of $\mathrm{Cu}_{2} \mathrm{Se}_{4}$ tetrahedral array separated by $\mathrm{BCSe}_{4}$ tetrahedral array. The $\mathrm{Cu}_{2} \mathrm{Se}_{4}$ tetrahedral array acts as an electrically conducting path and the $\mathrm{BCSe}_{4}$ tetrahedral array acts as an insulating unit. With $\mathrm{Cu}$ substitution of $\mathrm{B}^{\mathrm{II}}$ or $\mathrm{C}^{\mathrm{IV}}$ in the matrix, $\mathrm{Cu}_{2} \mathrm{Se}_{4}$ can induce more electrically conducting pathways in the crystal structure, resulting in decreased electrical resistivity [27]. Liu et al. [26] reported that the electrical conductivity of $10 \% \mathrm{Cu}$ doped $\mathrm{Cu}_{2} \mathrm{CdSnSe}_{4}$ could reach $1.89 \times 10^{4} \mathrm{~S} \mathrm{~m}^{-1}$, which was about six times than that of pure $\mathrm{Cu}_{2} \mathrm{CdSnSe}_{4}$ $\left(0.31 \times 10^{4} \mathrm{~S} \mathrm{~m}^{-1}\right)$. Excessive $\mathrm{Cu}$ doping was also induced to the $\mathrm{Cu}_{2} \mathrm{MnSnSe}_{4}$ system and the carrier concentration was increased from $0.21 \times 10^{20}$ to $2.89 \times 10^{20} \mathrm{~cm}^{-3}$ as shown in Fig. 3a. Thus a higher electrical conductivity of $2.49 \times 10^{4} \mathrm{~S} \mathrm{~m}^{-1}$ was achieved with $10 \% \mathrm{Cu}$ doped sample which was about eight times than that of undoped sample $\left(0.36 \times 10^{4} \mathrm{~S} \mathrm{~m}^{-1}\right)$ [28]. And the optimized electrical conductivity can also be achieved in $\mathrm{Cu}_{2+x} \mathrm{Zn}_{1-x} \mathrm{SnSe}_{4}$ and $\mathrm{Cu}_{2+x} \mathrm{ZnSn}_{1-x} \mathrm{Se}_{4}[16,27]$. As one can see, due to the fantastic crystal structure of the $\mathrm{Cu}_{2} \mathrm{~B}^{\mathrm{II}} \mathrm{C}^{\mathrm{VV}} \mathrm{Se}_{4}$, doping excessive $\mathrm{Cu}$ into the matrix can significantly decrease the huge electrical resistivity to a proper magnitude to achieve a higher $P F$.

Except for the non-stoichiometry method, the cation doping is also an effective way to increase the carrier
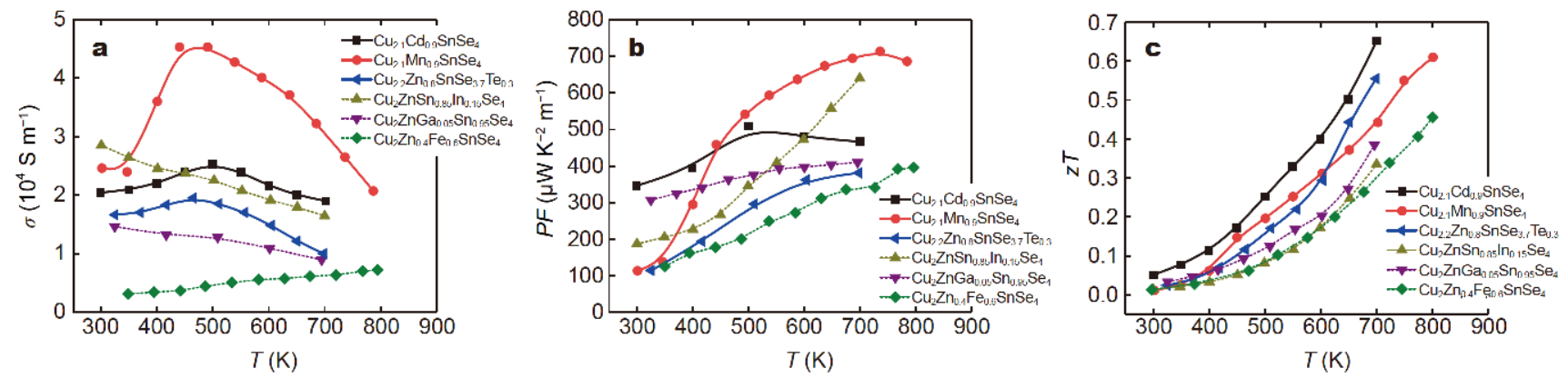

Figure 3 The improved (a) electrical conductivity, (b) $P F$, and (c) figure of merit via non-stoichiometry method $[15,26,28]($ solid lines) and cation doping $[17,29,30]$ (dash lines). 
concentration. With $15 \%$ In substitute for Sn site in the $\mathrm{Cu}_{2} \mathrm{ZnSnSe}_{4}$ system, the carrier concentration increased from $1 \times 10^{19}$ to $6 \times 10^{20} \mathrm{~cm}^{-3}$, leading to an increased electrical conductivity from $0.45 \times 10^{4}$ to $2.9 \times 10^{4} \mathrm{~S} \mathrm{~m}^{-1}$ [17]. The Fe cation substitute for $\mathrm{Zn}$ and the Ga cation substitute for Sn are other examples of this strategy [29,30]. The increased electrical conductivity is summarized and presented in the Fig. 3a. Due to the increased electrical conductivity via excessive $\mathrm{Cu}$ doping or cation doping, the PFs of doped samples get enhanced. As presented in Fig. $3 b$, the $P F_{\max }$ for $\mathrm{Cu}_{2.1} \mathrm{Mn}_{0.9} \mathrm{SnSe}_{4}$ is around $700 \mu \mathrm{W} \mathrm{K} \mathrm{K}^{-2} \mathrm{~m}^{-1}$ at $800 \mathrm{~K}$ which is 1.7 times larger than that of undoped samples $\left(400 \mu \mathrm{W} \mathrm{K} \mathrm{K}^{-1}\right.$ at $\left.800 \mathrm{~K}\right)$ [28]. With the merely changed thermal conductivity, the $z T$ s of the quaternary chalcogenides get increased as shown in Fig. 3c. A $z T_{\max }$ close to 0.7 for $\mathrm{Cu}_{2.1} \mathrm{Cd}_{0.9} \mathrm{SnSe}_{4}$ compared with a value of 0.4 for undoped $\mathrm{Cu}_{2} \mathrm{CdSnSe}_{4}$ [26]. As a conclusion, the variation in stoichiometry with excessive $\mathrm{Cu}$ doping and the cation doping are effective ways to increase the carrier concentration which leads to an optimized electrical conductivity and eventually a higher $P F$ and $z T$.

However, a higher carrier concentration on one hand is beneficial to obtaining a higher electrical conductivity, on the other hand leading to a lower $S$. Thus, the unity- $\eta$ rule and the anion doping are introduced to retard the decrease of $S$.

The unity- $\eta$ rule origins from the pseudo-cubic structure approach which indicates that diamond-like compounds with $\eta$ closer to 1 usually perform superior $S$ [19]. As illustrated before, the structure of the quaternary chalcogenides can be regarded as a double-periodic cubic zinc-blende supercell along the $z$-axis. Compared with the triply degenerated band $\Gamma_{15 v}$ of cubic zinc-blend structure in the valance band maximum, in quaternary chalcogenides structure, the $\Gamma_{15 \mathrm{v}}$ band splits into a double de- generated $\Gamma_{5 \mathrm{v}}$ bands and a non-degenerated $\Gamma_{4 \mathrm{v}}$ band due to the reduced crystal symmetry as shown in Fig. 4a. This, in turn, causes a band energy difference $\left(\Delta_{\mathrm{CF}}\right)$ between $\Gamma_{4 \mathrm{v}}$ and $\Gamma_{5 \mathrm{v}}$, leading to a lower density of state near the Fermi level and a lower $S$ eventually [20]. Thus the closer $\eta$ approaches to 1 , the closer $\Delta_{\mathrm{CF}}$ to 0 and consequently a better $S$. Song et al. [28] calculated that the $\Delta_{\mathrm{CF}}$ is only $0.02 \mathrm{eV}$ for the pure $\mathrm{Cu}_{2} \mathrm{MnSnSe}_{4}$. And according to the crystal structure analysis, the substitution of $\mathrm{Mn}$ by $\mathrm{Cu}$ merely changed the $\eta$ ( 0.9858 for undoped sample and 0.9869 for $\mathrm{Cu}_{2.1} \mathrm{Mn}_{0.9} \mathrm{SnSe}_{4}$ ), and thus the non-stoichiometric $\mathrm{Cu}_{2+x} \mathrm{Mn}_{1-x} \mathrm{SnSe}_{4}$ samples possessed similar $\Delta_{\mathrm{CF}}$. Consequently, the density of state effective mass $m^{*}$ remained as $1.2 m_{\mathrm{e}}$ ( $m_{\mathrm{e}}$ is the free electron mass), as presented in Fig. $4 \mathrm{~b}$. Thus the $S-p_{H}$ plots all lay on the Pisarenko line rather than below it. Besides, the relationship between the unity- $\eta$ law and $S$ was studied comprehensively in three quaternary chalcogenides $\mathrm{Cu}_{2} \mathrm{XSnSe}_{4}(\mathrm{X}=\mathrm{Mn}, \mathrm{Fe}, \mathrm{Co})$ [21]. According to the crystal structure analysis, the $\eta$ for $\mathrm{Cu}_{2} \mathrm{CoSnSe}_{4}$ and $\mathrm{Cu}_{2} \mathrm{FeSnSe}_{4}$ are 0.9997 and 0.9899 , respectively, which are higher than that of $\mathrm{Cu}_{2} \mathrm{MnSnSe}_{4}$ (0.9859). Thus the Seebeck coefficients of $\mathrm{Cu}_{2} \mathrm{CoSnSe}_{4}$ and $\mathrm{Cu}_{2} \mathrm{FeSnSe}_{4}$ are varied from the Pisarenko plot at room temperature as shown in Fig. 4b. And the values are higher than that of $\mathrm{Cu}_{2} \mathrm{MnSnSe}_{4}$ which possesses a relatively small $\eta$. Thus the $P F$ benefits from the increased $S$ due to unity- $\eta$ law as shown in Fig. 4c. The $P F s$ of $\mathrm{Cu}_{2} \mathrm{Zn}_{1-x} \mathrm{Fe}_{x} \mathrm{GeSe}_{4}$ are roughly increased with the increasing $\eta$ [31]. And the $P F s$ of $\mathrm{Cu}_{2} \mathrm{FeSnSe}_{4}$ and $\mathrm{Cu}_{2} \mathrm{CoSnSe}_{4}$ are also presented for comparison [21]. Especially, the $\mathrm{Cu}_{2} \mathrm{CoSnSe}_{4}$ obtains the highest $P F$ as compared with other samples due to the value of $\eta$ almost equal to unity. As the unity- $\eta$ law is so important for maintaining $S$, this law should be used to screen and select doping elements.

Except for the unity- $\eta$ law, anion doping is another way
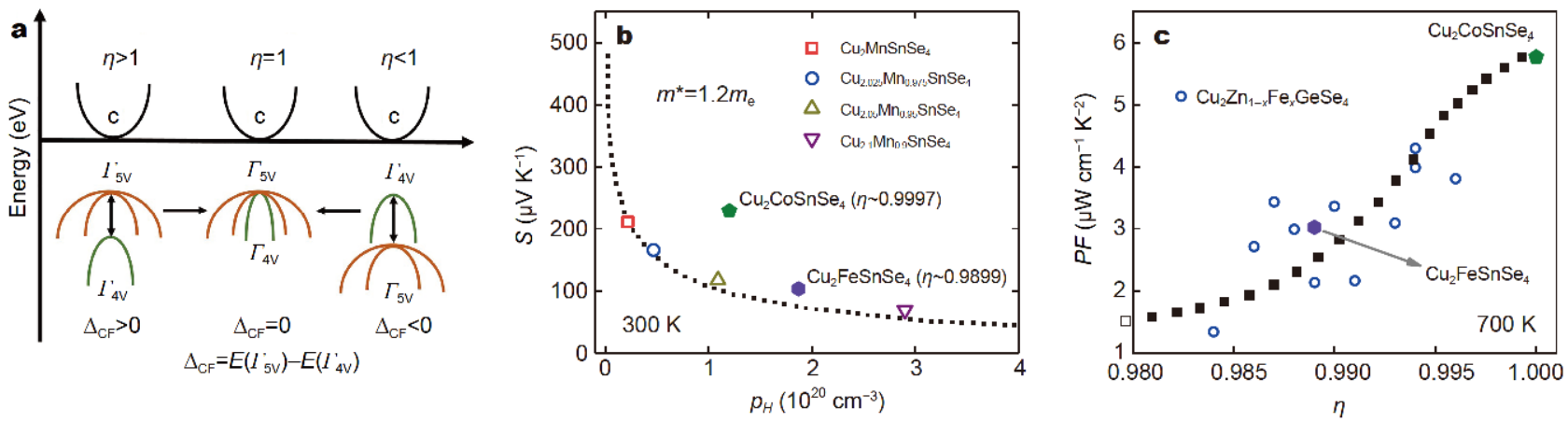

Figure 4 (a) The relationship between the band structure of the quaternary chalcogenides and the structure distortion parameter $\eta$ [21]. (b) The Pisarenko curve variation and (c) $P F$ with different structure distortion parameter $\eta[21,28,31]$. 
to increase $S$. But considering the huge electrical resistivity of the quaternary chalcogenides, the anion doping is more likely to adjust the carrier concentration to balance the conflict between $\sigma$ and $S$. And this strategy is often unitarily used with the non-stoichiometry method or the cation doping. Dong et al. [15] reported that with Te substitute for Se, $S$ of $\mathrm{Cu}_{2.2} \mathrm{Zn}_{0.8} \mathrm{SnSe}_{4-x} \mathrm{Te}_{x}$ got enhanced, from $120 \mu \mathrm{V} \mathrm{K}{ }^{-1}$ for $\mathrm{Cu}_{2.2} \mathrm{Zn}_{0.8} \mathrm{SnSe}_{3.9} \mathrm{Te}_{0.1}$ to $200 \mu \mathrm{V} \mathrm{K}^{-1}$ for $\mathrm{Cu}_{2.2} \mathrm{Zn}_{0.8} \mathrm{SnSe}_{3.6} \mathrm{Te}_{0.4}$ at $700 \mathrm{~K}$. Additionally, the band structure of the quaternary chalcogenides is mainly influenced by the anion atoms and this should be another reason for implementing anion doping in these materials. The calculation results show that the $\Gamma_{4 \mathrm{v}}$ and $\Gamma_{5 \mathrm{v}}$ bands reach the maximum at the $G$ point and the contribution is mainly from the $\mathrm{Cu} 3 \mathrm{~d}$ states and $\mathrm{Q} n \mathrm{p}(\mathrm{Q} n \mathrm{p}=\mathrm{S} 3 \mathrm{p}$, Se $4 \mathrm{p}$, Te $5 \mathrm{p})$ states $[19,26,28]$ as shown in Fig. 5. Meanwhile, the $\mathrm{Cu} 3 \mathrm{~d}$ orbitals are too localized to participate in the electrical transport, and thus the electrical transport properties should be mainly determined by the $\mathrm{Q}(\mathrm{Q}=\mathrm{S}, \mathrm{Se}, \mathrm{Te})$ atoms. Consequently, the anion doping should be an effective way to influence the electrical transport properties. But according to the reported results, the band gap will become larger with more hybridization of $\mathrm{Q} n \mathrm{p}$ and $\mathrm{Cu} 3 \mathrm{~d}$ which is unfavorable for the electrical conductivity [32]. Thus the anion doping method can be viewed as an alternative way to improve the $P F$ of the quaternary chalcogenides.

Summing up the strategies mentioned above, the intrinsic low electrical conductivity could be optimized via doping or forming excessive electrical transport channels by non-stoichiometry method. Though these ways lead to a decreased $S$, the unity- $\eta$ rule and anion doping are introduced to retard this decrease. Thus the synergistic effects of these methods are required to enhance the electrical properties of the quaternary chalcogenides.

\section{STRATEGIES TO OPTIMIZE THERMAL CONDUCTIVITY OF QUATERNARY CHALCOGENIDES}

As for the thermal transport optimization, though the thermal conductivity of the quaternary chalcogenides is quite low compared with traditional TE alloys as shown in Fig. 2a, there still have methods to decrease the thermal conductivity especially the lattice part. Among those strategies, alloying and nano-engineering are much more effective to suppress the lattice thermal conductivity.

Alloying is widely implemented in the quaternary chalcogenides to decrease the phonon propagation via mass and strain differences. As the high frequency acoustic phonons are predominant carriers of heat in the
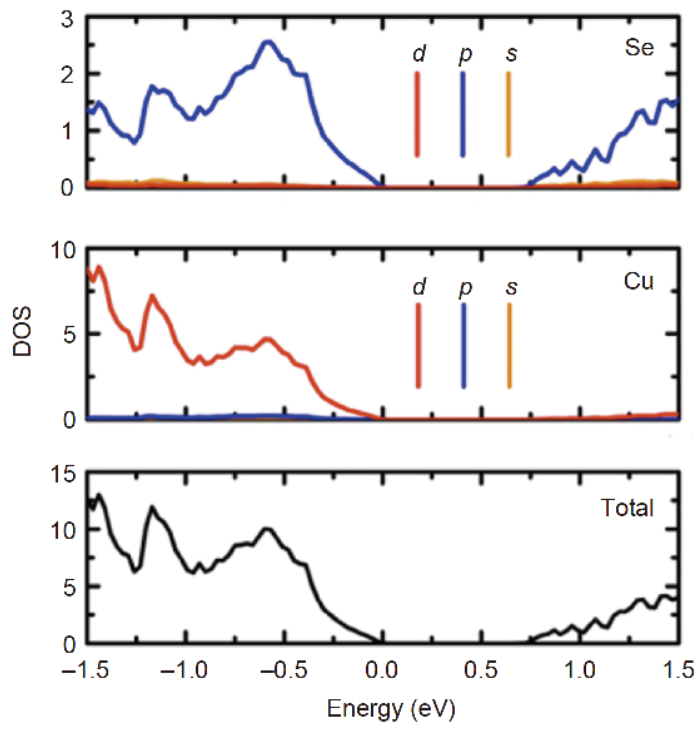

Figure 5 The calculated density of states for $\mathrm{Cu}_{2} \mathrm{MnSnSe}_{4}$ compound [28].

quaternary chalcogenides, the lattice thermal conductivity can be decreased significantly via alloying. For example, with $\mathrm{Cu}$ substitute of $\mathrm{Mn}$, the scattering parameter related to mass and strain fluctuation increases, leading to a decreased lattice thermal conductivity. For $\mathrm{Cu}_{2.1} \mathrm{Mn}_{0.9} \mathrm{SnSe}_{4}$, the lattice thermal conductivity is around $2.5 \mathrm{~W} \mathrm{~m}^{-1} \mathrm{~K}^{-1}$ at $300 \mathrm{~K}$ which is about $14 \%$ reduction as compared with the undoped samples [28]. And the effect of alloying on the lattice thermal conductivity was also reported in $\mathrm{Cu}_{2} \mathrm{Zn}_{1-x} \mathrm{Fe}_{x} \mathrm{GeSe}_{4}$ [31] and $\mathrm{Cu}_{2} \mathrm{Cd}_{1-x} \mathrm{Zn}_{x} \mathrm{SnSe}_{4}$ [33].

As for distortion of the low frequency acoustic phonons, nano-engineering has been proposed to further reduce the lattice thermal conductivity of the quaternary chalcogenides [34]. On the perspective of microstructure, the nano-structures can induce high density of interfaces in the matrix, and the size of nano-structures are similar to the low frequency acoustic phonon mean free path, hence resulting in phonon scattering which can effectively decrease the lattice thermal conductivity. Thus, nanoengineering as an improvement tool for decreasing the thermal conductivity has been introduced to many TE materials [35-37]. Similarly, nano-engineering can also be a practicable approach to adjust the thermal transport properties of the quaternary chalcogenides. In detail, the nano-structuring can be implemented via both physical and chemical ways. Ball milling (BM) and nano phase segregation are physical methods to form nanostructure. As for the chemical ways, colloidal synthesis and hot injection synthesis have been implied in the quaternary 
chalcogenides.

Homogeneous separation and nano-sized grain can be obtained via $\mathrm{BM}$, and thus this method has been widely used in the TE area, e.g., SiGe and PbTe [22,37]. Tiwari et al. [38] successfully synthesized the $\mathrm{Cu}_{2} \mathrm{ZnSnSe}_{4}$ nanopowder $(5.9 \mathrm{~nm})$ with the mechanical BM method and the crystallite size still remained as nano-size $(43.40 \mathrm{~nm})$ even after hot press. As presented in Fig. 6, with the reduced lattice thermal conductivity, the total thermal conductivity is only $1.13 \mathrm{~W} \mathrm{~m}^{-1} \mathrm{~K}^{-1}$. Nano phase separation (NPS) is another skillfully physical way to form the nanostructure in the quaternary chalcogenides. Nanosized impurities can be formed via phase segregation at higher $\mathrm{Cu}$ doping content in $\mathrm{Cu}_{2+x} \mathrm{Zn}_{1-x} \mathrm{GeSe}_{4}$ system [39]. Due to the chemical imbalance, $250 \mathrm{~nm} \mathrm{Cu}_{2-x} \mathrm{Se}$ grains are formed and mainly located at the grain boundary, leading to a minimum lattice thermal conductivity value of $0.6 \mathrm{~W} \mathrm{~m}^{-1} \mathrm{~K}^{-1}$ at high temperature. In conclusion, these two methods are simple and effective strategies to decrease the thermal conductivity of quaternary chalcogenides, but this effect is more significant at high temperature.

The chemical approaches such as colloidal synthesis and hot injection synthesis are induced to decrease the thermal conductivity in the whole temperature range. Ibanez et al. $[40,41]$ synthesized the $\mathrm{Cu}_{2+x} \mathrm{Cd}_{1-x} \mathrm{SnSe}_{4}$ and $\mathrm{Cu}_{2+x} \mathrm{Zn}_{1-x} \mathrm{GeSe}_{4}$ nanocrystals using the colloidal synthesis method. The reaction progress and the grain size can be well controlled via adjusting the reaction conditions. Especially for the $\mathrm{Cu}_{2.15} \mathrm{Zn}_{0.85} \mathrm{GeSe}_{4}$ specimen, the low total thermal conductivity $0.5 \mathrm{~W} \mathrm{~m}^{-1} \mathrm{~K}^{-1}$ is maintained from 373 to $873 \mathrm{~K}$ as shown in Fig. 6a [41]. As part of the total thermal conductivity, the lattice thermal conductivity must be lower than $0.5 \mathrm{~W} \mathrm{~m}^{-1} \mathrm{~K}^{-1}$. Hot injection synthesis is another chemical method to obtain nano powder of quaternary chalcogenides as Chen et al. reported [42]. The $\mathrm{Cu}_{2} \mathrm{ZnSnSe}_{4}$ nanocrystal which consists with nano-particle via excessive $\mathrm{Cu}$ doping is obtained using this method. Due to the increased boundary scattering of phonons resulting from the nanocrystal, the lattice thermal conductivity is decreased to $0.46 \mathrm{~W} \mathrm{~m}^{-1} \mathrm{~K}^{-1}$ in $\mathrm{Cu}_{2.1} \mathrm{Zn}_{0.9} \mathrm{SnSe}_{4}$, and such low lattice thermal conductivity is even smaller than that in the allscale-phonon-scattered PbTe materials [35,43]. Finally, a high $z T$ of 0.7 is achieved for $\mathrm{Cu}_{2.1} \mathrm{Zn}_{0.9} \mathrm{SnSe}_{4}$ as shown in Fig. $6 \mathrm{~b}$. Generally, with the well purification and accurate adjustment of experimental conditions, chemical approach is a convenient and fast way to obtain nano powder of quaternary chalcogenides to further optimize the thermal conductivity.

As mentioned above, alloying can not only adjust the carrier concentration but also be commenly used in quaternary chalcogenides to decrease the lattice thermal conductivity. Besides, nano-structuring, a way widely used in many TE material systems, can also play an important role in reducing the thermal conductivity. No matter physical or chemical ways, nano-structuring is proved as an effective way to furthur enhance the $z T$ (Fig. 6b) of the $\mathrm{Cu}_{2} \mathrm{~B}^{\mathrm{II}} \mathrm{C}^{\mathrm{IV}} \mathrm{Se}_{4}$ system with the improved electrical properties.

With the relatively low intrinsic thermal conductivity in middle temperature range, $\mathrm{Cu}_{2} \mathrm{~B}^{\mathrm{II}} \mathrm{C}^{\mathrm{IV}} \mathrm{Se}_{4}$ group could be a promising material exhibiting high TE performance. Herein, the current research progress on $\mathrm{Cu}_{2} \mathrm{~B}^{\mathrm{II}} \mathrm{C}^{\mathrm{IV}} \mathrm{Se}_{4}$ alloys has been reviewed and the successful strategies for optimizing TE performance have been focused. The carrier concentration can be adjusted via non-stoichiometry method and cation doping. Along with the maintained $S$ through unity- $\eta$ law or anion doping, the electrical properties of the $\mathrm{Cu}_{2} \mathrm{~B}^{\mathrm{II}} \mathrm{C}^{\mathrm{IV}} \mathrm{Se}_{4}$ compounds could be well
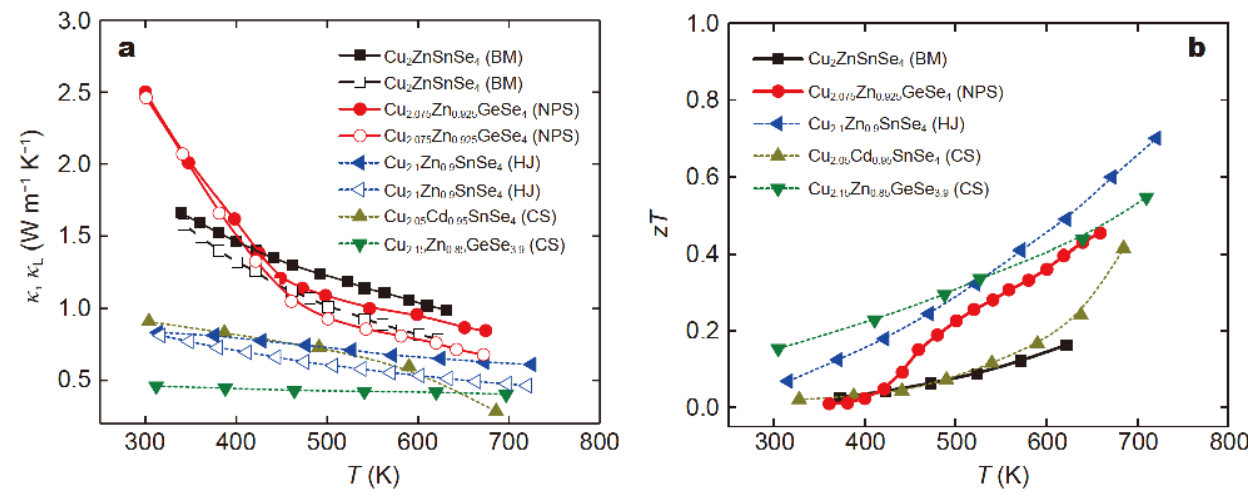

Figure 6 (a) The further reduced total thermal conductivity (solid) and lattice thermal conductivity (open) using physical methods [38,39] (solid lines) and chemical methods [40-42] (dash lines). (b) The enhanced figure of merit through nano-structuring [38-42]. 
optimized. The lattice thermal conductivity can be further decreased using alloying, BM, nano phase separation, colloidal synthesis and hot injection synthesis. Similar to other TE materials, the synergistic effect of these methods should be introduced to the quaternary chalcogenides. It is believed that with the collective effect of these strategies, the quaternary chalcogenides are promising robust TE material system. Though the $z T$ of $\mathrm{Cu}_{2} \mathrm{~B}^{\mathrm{II}} \mathrm{C}^{\mathrm{IV}} \mathrm{Se}_{4}$ has been improved with doping and nano-structuring, new concepts, mechanisms and techniques are still demanded to further boost the TE performance of the quaternary chalcogenides.

Received 16 May 2019; accepted 27 June 2019; published online 17 July 2019

1 Bell LE. Cooling, heating, generating power, and recovering waste heat with thermoelectric systems. Science, 2008, 321: 1457-1461

2 Zebarjadi M, Esfarjani K, Dresselhaus MS, et al. Perspectives on thermoelectrics: from fundamentals to device applications. Energy Environ Sci, 2012, 5: 5147-5162

3 Gayner C, Kar KK. Recent advances in thermoelectric materials. Prog Mater Sci, 2016, 83: 330-382

4 Chasmar RP, Stratton R. The thermoelectric figure of merit and its relation to thermoelectric generators. J Electron Control, 1959, 7: 52-72

5 Zhu T, Liu Y, Fu C, et al. Compromise and synergy in highefficiency thermoelectric materials. Adv Mater, 2017, 29: 1605884

6 Pei Y, LaLonde A, Iwanaga S, et al. High thermoelectric figure of merit in heavy hole dominated PbTe. Energy Environ Sci, 2011, 4: 2085-2089

7 Wang H, Hwang J, Zhang C, et al. Enhancement of the thermoelectric performance of bulk SnTe alloys via the synergistic effect of band structure modification and chemical bond softening. J Mater Chem A, 2017, 5: 14165-14173

8 Zhang Q, Liao B, Lan Y, et al. High thermoelectric performance by resonant dopant indium in nanostructured SnTe. Proc Natl Acad Sci USA, 2013, 110: 13261-13266

9 Heremans JP, Jovovic V, Toberer ES, et al. Enhancement of thermoelectric efficiency in $\mathrm{PbTe}$ by distortion of the electronic density of states. Science, 2008, 321: 554-557

10 Faleev SV, Léonard F. Theory of enhancement of thermoelectric properties of materials with nanoinclusions. Phys Rev B, 2008, 77: 214304

11 Lim KH, Wong KW, Liu Y, et al. Critical role of nanoinclusions in silver selenide nanocomposites as a promising room temperature thermoelectric material. J Mater Chem C, 2019, 7: 2646-2652

12 Wang $\mathrm{H}$, Bahk JH, Kang C, et al. Right sizes of nano- and microstructures for high-performance and rigid bulk thermoelectrics. Proc Natl Acad Sci USA, 2014, 111: 10949-10954

13 Brown SR, Kauzlarich SM, Gascoin F, et al. $\mathrm{Yb}_{14} \mathrm{MnSb}_{11}$ : new high efficiency thermoelectric material for power generation. Chem Mater, 2006, 18: 1873-1877

14 Zhao LD, Lo SH, Zhang Y, et al. Ultralow thermal conductivity and high thermoelectric figure of merit in SnSe crystals. Nature, 2014, 508: $373-377$

15 Dong $\mathrm{Y}$, Eckert B, Wang $\mathrm{H}$, et al. Synthesis, crystal structure, and transport properties of $\mathrm{Cu}_{2.2} \mathrm{Zn}_{0.8} \mathrm{SnSe}_{4-x} \mathrm{Te}_{x}(0.1 \leq x \leq 0.4)$. Dalton
Trans, 2015, 44: 9014-9019

16 Dong Y, Wang H, Nolas GS. Synthesis and thermoelectric properties of $\mathrm{Cu}$ excess $\mathrm{Cu}_{2} \mathrm{ZnSnSe}_{4}$. Phys Status Solidi RRL, 2014, 8: 61-64

17 Shi XY, Huang FQ, Liu ML, et al. Thermoelectric properties of tetrahedrally bonded wide-gap stannite compounds $\mathrm{Cu}_{2} \mathrm{ZnSn}_{1-x}$ $\mathrm{In}_{x} \mathrm{Se}_{4}$. Appl Phys Lett, 2009, 94: 122103

18 Kumta PN, Risbud SH. Rare-earth chalcogenides-an emerging class of optical materials. J Mater Sci, 1994, 29: 1135-1158

19 Zhang J, Liu R, Cheng N, et al. High-performance pseudocubic thermoelectric materials from non-cubic chalcopyrite compounds. Adv Mater, 2014, 26: 3848-3853

20 Wei TR, Qin Y, Deng T, et al. Copper chalcogenide thermoelectric materials. Sci China Mater, 2019, 62: 8-24

21 Song Q, Qiu P, Hao F, et al. Quaternary pseudocubic $\mathrm{Cu}_{2} \mathrm{TMSnSe}_{4}$ $(\mathrm{TM}=\mathrm{Mn}, \mathrm{Fe}, \mathrm{Co})$ chalcopyrite thermoelectric materials. Adv Electron Mater, 2016, 2: 1600312

22 Bathula S, Jayasimhadri M, Gahtori B, et al. Enhancement in thermoelectric performance of SiGe nanoalloys dispersed with $\mathrm{SiC}$ nanoparticles. Phys Chem Chem Phys, 2017, 19: 25180-25185

23 Zhu Y, Liu Y, Ren G, et al. Lattice dynamics and thermal conductivity in $\mathrm{Cu}_{2} \mathrm{Zn}_{1-x} \mathrm{Co}_{x} \mathrm{SnSe}_{4}$. Inorg Chem, 2018, 57: 6051-6056

24 Chetty R, Bali A, Mallik RC. Thermoelectric properties of indium doped $\mathrm{Cu}_{2} \mathrm{CdSnSe}_{4}$. Intermetallics, 2016, 72: 17-24

25 Xiao $\mathrm{Y}, \mathrm{Wu} \mathrm{H}, \mathrm{Li} \mathrm{W}$, et al. Remarkable roles of $\mathrm{Cu}$ to synergistically optimize phonon and carrier transport in n-type $\mathrm{PbTe}-\mathrm{Cu}_{2} \mathrm{Te}$. J Am Chem Soc, 2017, 139: 18732-18738

26 Liu ML, Chen IW, Huang FQ, et al. Improved thermoelectric properties of $\mathrm{Cu}$-doped quaternary chalcogenides of $\mathrm{Cu}_{2} \mathrm{CdSnSe}_{4}$. Adv Mater, 2009, 21: 3808-3812

27 Raju C, Falmbigl M, Rogl P, et al. Thermoelectric properties of chalcogenide based $\mathrm{Cu}_{2+x} \mathrm{ZnSn}_{1-x} \mathrm{Se}_{4}$. AIP Adv, 2013, 3: 032106

28 Song $\mathrm{Q}$, Qiu $\mathrm{P}$, Chen $\mathrm{H}$, et al. Improved thermoelectric performance in nonstoichiometric $\mathrm{Cu}_{2+\delta} \mathrm{Mn}_{1-\delta} \mathrm{SnSe}_{4}$ quaternary diamondlike compounds. ACS Appl Mater Interfaces, 2018, 10: 10123-10131

29 Dong Y, Wang H, Nolas GS. Synthesis, crystal structure, and high temperature transport properties of p-type $\mathrm{Cu}_{2} \mathrm{Zn}_{1-x} \mathrm{Fe}_{x} \mathrm{SnSe}_{4}$. Inorg Chem, 2013, 52: 14364-14367

30 Wei K, Beauchemin L, Wang $\mathrm{H}$, et al. Enhanced thermoelectric properties of $\mathrm{Cu}_{2} \mathrm{ZnSnSe}_{4}$ with Ga-doping. J Alloys Compd, 2015, 650: 844-847

31 Zeier WG, Pei Y, Pomrehn G, et al. Phonon scattering through a local anisotropic structural disorder in the thermoelectric solid solution $\mathrm{Cu}_{2} \mathrm{Zn}_{1-x} \mathrm{Fe}_{x} \mathrm{GeSe}_{4}$. J Am Chem Soc, 2013, 135: 726-732

32 Liu ML, Huang FQ, Chen LD, et al. A wide-band-gap p-type thermoelectric material based on quaternary chalcogenides of $\mathrm{Cu}_{2} \mathrm{ZnSnQ}_{4}(\mathrm{Q}=\mathrm{S}, \mathrm{Se})$. Appl Phys Lett, 2009, 94: 202103

33 Liu FS, Wang B, Ao WQ, et al. Crystal structure and thermoelectric properties of $\mathrm{Cu}_{2} \mathrm{Cd}_{1-x} \mathrm{Zn}_{x} \mathrm{SnSe}_{4}$ solid solutions. Intermetallics, 2014, 55: 15-21

34 Kanatzidis MG. Nanostructured thermoelectrics: the new paradigm? Chem Mater, 2010, 22: 648-659

35 Zhao LD, Wu HJ, Hao SQ, et al. All-scale hierarchical thermoelectrics: $\mathrm{MgTe}$ in $\mathrm{PbTe}$ facilitates valence band convergence and suppresses bipolar thermal transport for high performance. Energy Environ Sci, 2013, 6: 3346-3355

36 Li Z, Chen Y, Li JF, et al. Systhesizing SnTe nanocrystals leading to thermoelectric performance enhancement via an ultra-fast microwave hydrothermal method. Nano Energy, 2016, 28: 78-86 
37 Li ZY, Li JF, Zhao WY, et al. PbTe-based thermoelectric nanocomposites with reduced thermal conductivity by $\mathrm{SiC}$ nanodispersion. Appl Phys Lett, 2014, 104: 113905

38 Tiwari KJ, Prem Kumar DS, Mallik RC, et al. Ball mill synthesis of bulk quaternary $\mathrm{Cu}_{2} \mathrm{ZnSnSe}_{4}$ and thermoelectric studies. J Elec Materi, 2017, 46: 30-39

39 Zeier WG, LaLonde A, Gibbs ZM, et al. Influence of a nano phase segregation on the thermoelectric properties of the p-type doped stannite compound $\mathrm{Cu}_{2+x} \mathrm{Zn}_{1-x} \mathrm{GeSe}_{4}$. J Am Chem Soc, 2012, 134: 7147-7154

40 Ibáñez M, Cadavid D, Zamani R, et al. Composition control and thermoelectric properties of quaternary chalcogenide nanocrystals: the case of stannite $\mathrm{Cu}_{2} \mathrm{CdSnSe}_{4}$. Chem Mater, 2012, 24: 562-570

41 Ibáñez $\mathrm{M}$, Zamani $\mathrm{R}$, LaLonde $\mathrm{A}$, et al. $\mathrm{Cu}_{2} \mathrm{ZnGeSe}_{4}$ nanocrystals: synthesis and thermoelectric properties. J Am Chem Soc, 2012, 134: 4060-4063

42 Chen D, Zhao Y, Chen Y, et al. Hot-injection synthesis of $\mathrm{Cu}-$ doped $\mathrm{Cu}_{2} \mathrm{ZnSnSe}_{4}$ nanocrystals to reach thermoelectric $z T$ of 0.70 at $450^{\circ} \mathrm{C}$. ACS Appl Mater Interfaces, 2015, 7: 24403-24408

43 Biswas K, He J, Blum ID, et al. High-performance bulk thermoelectrics with all-scale hierarchical architectures. Nature, 2012, 489: 414-418

Acknowledgements The work was financially supported by the National Basic Research Program of China (2013CB632506), the National Natural Science Foundation of China (51871134, 51672159, 51501105 and 51611540342), Shandong Provincial Natural Science Foundation, China (ZR2019MEM007), the Young Scholars Program of Shandong University (2015WLJH21), China Postdoctoral Science Foundation (2015M580588 and 2016T90631), the Postdoctoral Innovation Foundation of Shandong Province (201603027), and the Foundation of the State Key Laboratory of Metastable Materials Science and Technology (201703).

Author contributions Wang $\mathrm{T}$ and Huo $\mathrm{T}$ wrote the paper; Wang $\mathrm{H}$ and Wang $\mathrm{C}$ guided the writing of this paper. All authors contributed to the general discussion.

Conflict of interest The authors declare that they have no conflict of interest.

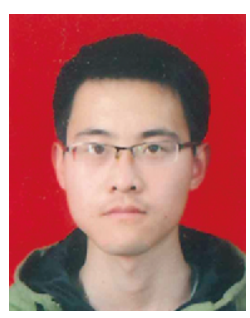

Teng Wang received his Bachelor degree in 2014 from Shandong Normal University. He is now a $\mathrm{PhD}$ candidate at Shandong University. His research interest is the thermoelectric properties of n-type $\mathrm{CaMnO}_{3}$ and p-type SnTe alloys.

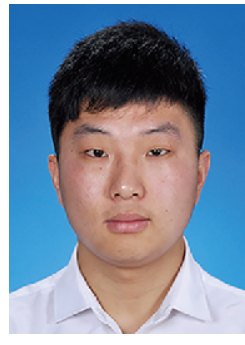

Taichang Huo received his Bachelor degree in 2018 from Ludong University. He is now a Master degree candidate at Shandong University. His research interest is the thermoelectric properties of the quaternary chalcogenide alloys.

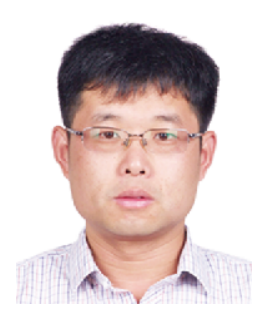

Hongchao Wang is currently an associate professor at Shandong University, China. He received his Bachelor degree in physics from Ludong University in 2006 and his $\mathrm{PhD}$ degree in material physics and chemistry from Shandong University in 2011. He was the BK post-doctoral researcher fellow at Yonsei University from 2012 to 2015. His current major research interest is thermoelectric materials and their physical properties.

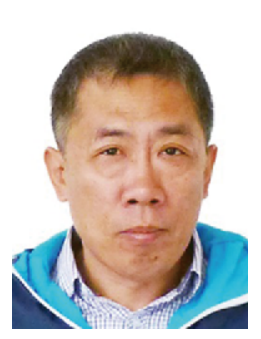

Chunlei Wang, born in China in 1963, studied physics at Shandong University where he gained his BSc degree in 1983 and MSc degree in 1986. He received his $\mathrm{PhD}$ in 1996 at Essex University, UK. He became a staff member at the Department of Physics of Shandong University in 1986, and Professor of physics in 1997.

\section{四元硫属化合物: 具有潜在应用价值的热电材料 及其最新进展}

王腾 $^{1 \dagger}$, 霍太昌 ${ }^{1 \dagger}$, 王洪超 ${ }^{1,2^{*}}$, 王春雷 ${ }^{{ }^{*}}$

摘要 热电材料利用Seebeck与Peltier效应可以实现热能和电能的 相互转化, 是颇具潜力的新型功能材料. 本文聚焦四元硫属化合物 $\mathrm{Cu}_{2} \mathrm{~B}^{\mathrm{II}} \mathrm{C}^{\mathrm{IV}} \mathrm{Se}_{4}$ (其中, $\mathrm{B}$ 位为 $\mathrm{Zn}, \mathrm{Cd}, \mathrm{Mn}, \mathrm{Hg}, \mathrm{C}$ 位为 $\mathrm{Si}, \mathrm{Ge}, \mathrm{Sn}$ ) 的热电 性能. 此类材料具有复杂的晶格结构, 导致其具有较低的晶格热导 率, 是一类具有本征低热导的热电材料. 本文系统地总结了各类优 化四元硫属化合物电学及热学的方法. 首先, 非化学计量法、元素 掺杂和 $\eta=1$ 定理用于改善其电学性能. 然后, 纳米结构工程可用于 进一步降低其热导率. 最后, 基于文中的论述, 我们提出通过多种 实验方法的结合使用, 协同调控四元硫属化合物的电、热性能, 以 期进一步提高其热电性能. 